\title{
Development of a Digital Decision-Making Algorithm to Increase Agricultural Productivity
}

\author{
I N Besaliev ${ }^{1}$, I P Bolodurina ${ }^{1,2}$, S S Akimov ${ }^{1,2^{*}}$
}

\author{
${ }^{1}$ Federal Research Centre of Biological Systems and Agro-technologies of the Russian Academy of Sciences, 29, 9 \\ January Street, Orenburg, 460000, Russia \\ ${ }^{2}$ Orenburg State University, 13, Pobedi Ave., Orenburg, 460018, Russia \\ *Corresponding author. Email: sergey_akimov_work@mail.ru
}

\begin{abstract}
The paper is devoted to the development of a digital decision-making algorithm in the field of agricultural productivity. The agro-industrial complex is currently one of the most promising areas of application of modern digital technologies. At the same time, the most important branch of agriculture is crop production, in which, at present, the transition to digital technologies is carried out quite poorly. The solution to this problem can be digital technologies, which are designed to solve a number of tasks, the key of which is to increase the productivity of crop production enterprises. It is obvious that the current climate changes can have significant impact on the results of the activities of a number of agricultural enterprises, which requires the development of special corrective measures, as a rule, using agricultural technologies. In this paper, a grain mass is taken as an indicator of productivity. Productivity was assessed by studying the influence of agro-climatic factors on it, including temperature and humidity indicators. In addition, the calculations include the presence or absence of fertilizers, as well as factors related to the technology of cultivation - the seeding rate and sowing dates. The influence of agro-climatic factors on the wheat grain mass was evaluated by regression analysis using the least squares method. The result of this research is the developed regression equations of the influence of agroclimatic factors on the grain mass. Further studies were based on forecasts of agro-climatic factors, which made it possible to predict the grain mass for the next three-year period. The obtained data allow us to make an optimal choice of sowing dates and seeding rates, taking into account the forecast of temperature and humidity. In order to further use the obtained equations, a digital decision-making algorithm was developed, which can become the basis for the development of a decision support system. The obtained digital decision-making algorithm allows you to make forecasts of grain mass for the upcoming period by selecting the optimal sowing dates and seeding rates.
\end{abstract}

Keywords: digital decision-making algorithm, agricultural productivity, agro-climatic factors, regression

equations

\section{INTRODUCTION}

Currently, a wide variety of information, digital and telecommunications resources are widely distributed in Russia, which leads to an active change in the concept of management towards digitalization, which is characteristic of all industries and spheres of human activity. The development and application of various software products, digital and Internet technologies are designed to improve the mechanisms of interaction between various structures, develop communication channels and reorganize management systems as a whole.

One of the promising areas for the use of modern digital technologies is the agro-industrial complex. Information technologies in this sphere are the most important resource for influencing the system of low-cost, sustainable agricultural production, improving the quality and safety of agricultural work, reducing the anthropogenic load on the environment and production losses [1].

In order to reduce the lag in labor productivity, land productivity and other indicators from countries with traditionally developed agriculture in the Russian Federation more and more attention is being paid to the development of state support measures to stimulate the development of digital technologies in the agricultural sector [2].

Crop production is an important branch of agriculture. Crop production provides a significant part of the consumption of agricultural products, and, in addition, is a supplier of forage for livestock.

As part of the implementation of digital technologies in the field of crop production, such tasks are solved as: increasing labor productivity; increasing export revenue; maximizing the value of industry enterprises; increasing economic growth rates of farms; creating an effective sales chain from producer to consumer; integration into related sectors of the 
digital economy; increasing the attractiveness of work in crop production [3].

At the same time, we can note that productivity is the key indicator of the effectiveness of any plant growing enterprise. Productivity indicators for crop farms specializing in the cultivation of cereals are the yield per area, or the mass of collected seeds [4].

The main agricultural crop in Russia is wheat, which is grown in the Orenburg region as well. This culture has fairly high requirements for growing conditions.

The productivity and yield of various types of wheat are influenced by many factors [5]. However, the most important of them are the agro-climatic features of a particular region, characterized by a certain climate, as well as certain conditions for the cultivation of cereals, based on agricultural technologies.

Current climate changes can have a significant impact on the final productivity of an agricultural enterprise and, as a result, require correction by methods of agricultural technologies. At the same time, it is necessary to obtain accurate and reliable data on changes in climate conditions and their impact on productivity, which will allow enterprises to use their land, labor, financial and other resources most effectively. It is also important to determine the main parameters of agricultural technologies, which include sowing dates, fertilization and seeding rates. Accounting for all these parameters is quite complex and requires the use of special mathematical methods of analysis, on the basis of which it will be possible to develop a decision support system for increasing the productivity of agricultural enterprises in the future.

\section{RELATED WORK}

A large number of Russian and foreign scientists have worked on the impact of climate factors on the final productivity of agricultural enterprises.

Among foreign scientists are P. Toscanoa, L. Genesio, A. Crisci, F..P Vaccari, E. Ferrari, P. La Cava, J. R. Porterde, and B. Gioli, who created an empirical linear model for predicting wheat yields based on weather forecasts in Italian regions with a markedly changing climate [6].

G. R. Brankovic, D. Dodig, M. Z. Zoric, G. G. SultanMomirovic, V. Dragicevic, and N. Duric used the regression modeling method to consider the impact of agroclimatic factors in Serbia on the final characteristics of wheat grain, such as yield and quality [7].

Asseng S, Bar-Tal A., Bowden J. W., Keating B. A., Van Herwaarden A., Palta J. A., Huth N. I., Probert M. E. using a simulation model of the crop production system, which includes various agrochemical and climatic factors, predicted changes in yield and quality of wheat grain for forest-steppe zones [8].

Hollins P. D., Kettlewell P.S., Peltonen-Sainio P., and Atkinson M. D. developed a model for predictive regression of winter wheat based on weather forecasts in Finland using complex mathematical methods [9].

Haboudane D., Miller J. R., Tremblay N., Zarco-Tejada P. J., Dextraze L. use the method of integrated narrow-band vegetation indices to predict crop yield and composition, for use in precision agriculture [10].

A lot of research is given in works of Russian scientists.

A.I. Brushkov carried out mathematical modeling of quantitative relationships in the multifactor system "weather - soil - fertilizer - plant - crop" (based on data from the Chelyabinsk region), and this system is currently the scientific basis for innovative technologies for cultivating grain crops [11].

G. V. Degtyaryova developed a physical and statistical method of spring wheat grain mass on Chernozem (black earth) soils in relation to weather factors using various models. The obtained equations allow us to quickly calculate the relationship between the amount of grain of the upcoming crop and the agrometeorological conditions of the pre-sowing period [12].

I. V. Pakhotina, Yu. V. Kolmakov, and M. G. Evdokimov were able to prove using data collected from fields in the south of Western Siberia that excessive precipitation significantly affects the mass of wheat grain, and that drought during the generative period caused the formation of a much smaller wheat core [13].

M. A. Stroganova developed a model, the concept of which is a constant, continuous growth of the crop, and, consequently, the productivity functions should be strictly linked to time; the developed dynamic models of crop formation are considered as models of the production process, designed to quantify the chemical composition of plants during the period from sowing to harvesting, especially for evaluating the economically valuable part of the crop [14].

V. N. Pavlova's work reveals approaches to solving the problem of assessing the impact of changes in climate conditions on agricultural productivity and considers models of the "weather-crop" system based on difference regression equations. It is determined that the elimination of yield trends by difference regression equations can significantly increase the accuracy and reliability of estimates of the impact of fluctuations on productivity [15]. S. A. Tobratov, O. S. Zheleznova based on data on winter wheat yield revealed the key factors of the modern climate that determine the value of bio-productivity of various types of agrocenoses [16].

Thus, the review showed that a number of authors use different mathematical approaches to describe and predict yield. However, there are very few attempts to create estimation and forecasting algorithms, which makes it difficult to optimize the work of agricultural enterprises.

The purpose of this work is to develop a decision - making algorithm for agricultural enterprises in the field of agricultural productivity management through the optimal selection terms and norms for sowing wheat seeds. 


\section{MATERIALS AND METHODS}

The mass of 1000 wheat grains was taken as the resulting indicator. The paper uses experimental material to estimate the mass of spring durum wheat grains zoned in the sharply continental climate of the Central zone of the Orenburg region. Experiments were conducted on southern, carbonate, medium-sized, heavy-loam Chernozem (black earth) with a humus content of $0-30 \mathrm{~cm} 3.5-4.2 \%$, total nitrogen $0.22-0.32 \%$, total phosphorus $1.6-2.7 \mathrm{mg}$ and exchange potassium $35-42 \mathrm{mg}$ per $100 \mathrm{~g}$ of dry soil. The $\mathrm{PH}$ of the soil solution is 7.1-8.2, the sum of the absorbed bases is not more than $40.2 \mathrm{mg} / \mathrm{EQ}$. per $100 \mathrm{~g}$ of dry soil.

The observations were made using the method of state variety testing of agricultural crops. The following agroclimatic factors were selected:

- availability of fertilizers, yes / no $(x 1)$;

- average daily air temperature, $\mathrm{t}^{\circ} \mathrm{C}(x 2)$;

- amount of precipitation, $\mathrm{mm}(x 3)$;

- average relative air humidity, $\%(x 4)$;

- average moisture deficit, $\mathrm{hPa}(x 5)$.

In addition, the paper considers three different sowing dates and three different seeding rates.

Widely used statistical methods and models are used as a methodological base. Verification of the data belonging to the normal distribution law was performed using the Shapiro-Wilk W-test. The relationship between the indicators was estimated using a nonparametric Spearman correlation coefficient. The regression equations were based on the least squares method, and the significance of the obtained regression coefficients was evaluated using the Fischer F-test. Statistical data was processed using the MS Excel and Statistica 8.0 application software package. Here is a mathematical interpretation of the problem..
Let $d$ be applied fertilizers, $Q=\left\{q_{1}, q_{2}, \ldots, q_{\beta}\right\}$ - various agroclimatic factors, and $B=\left\{b_{1}, b_{2}, \ldots, b_{\phi}\right\}-$ factors related to cultivation technology. Productivity $U$ can be described by the function $F$, depending on the fertilizer applied $d$, the indicated agroclimatic factors $Q$, and the cultivation technology $B$. The applied fertilizer factor $d$ and the cultivation technology $B$ are controlling influences on the final productivity, since these factors can be adjusted to achieve maximum returns from agricultural producers. Thus, the productivity of $U$, depending on the applied fertilizers, agroclimatic factors and cultivation technology can be described by the following relation:

$$
U=F(d, Q, B) \rightarrow \max
$$

The obtained ratio allows optimizing the productivity of agricultural enterprises by correcting agro-climatic data by applying fertilizers and changing the cultivation technology.

\section{RESULTS AND DISCUSSION}

The study of indicators using correlation analysis methods revealed multicollinearity between some indicators. To eliminate it, the model was modified, leaving only three factors in it:

- availability of fertilizers, yes / no $(x 1)$;

- average daily air temperature, $\mathrm{t}^{\circ} \mathrm{C}(x 2)$;

- amount of precipitation, $\mathrm{mm}(x 3)$.

The least squares method is used to obtain regression equations for each of the combinations "sowing date sowing rate". The obtained regression equations are shown in table 1.

Table 1 Regression equations of the dependence of productivity on agro-climatic and agro-technological factors

\begin{tabular}{|c|c|c|c|}
\hline \multirow{2}{*}{$\begin{array}{c}\text { Sowing } \\
\text { dates }\end{array}$} & \multicolumn{3}{|c|}{ Seeding rate, $\mathrm{kg} / \mathrm{ha}$} \\
\hline & 2,5 & 3,5 & 4,5 \\
\hline $\begin{array}{c}1 \\
\text { period }\end{array}$ & $\begin{array}{c}y=170,61+0,767 x_{1-5,86 x_{2}-} \\
0,189 x_{3}\end{array}$ & $\begin{array}{c}y=117,41+0,133 x_{1}-3,03 x_{2^{-}} \\
0,271 x_{3}\end{array}$ & $\begin{array}{c}y=100,915+1,533 x_{1}-2,21 x_{2}- \\
0,339 x_{3}\end{array}$ \\
\hline $\begin{array}{c}2 \\
\text { period } \\
\end{array}$ & $\begin{array}{c}y=16,631+0,5 x_{1}-2,767 x_{2-} \\
0,468 x_{3}\end{array}$ & $\begin{array}{c}y=15,014+0,6 x_{1}-4,397 x_{2^{-}} \\
1,246 x_{3}\end{array}$ & $\begin{array}{c}y=55,974+1,167 x_{1}-2,115 x_{2}- \\
1,294 x_{3}\end{array}$ \\
\hline $\begin{array}{c}3 \\
\text { period }\end{array}$ & $\begin{array}{c}y=14,609+0,577 x_{1^{-}} 0,414 x_{2^{-}} \\
0,689 x_{3}\end{array}$ & $\begin{array}{c}y=28,798+0,275 x_{1}-2,221 x_{2}- \\
1,033 x_{3}\end{array}$ & $\begin{array}{c}y=2,33+0,242 x_{1}-1,921 x_{2^{-}} \\
0,43 x_{3}\end{array}$ \\
\hline
\end{tabular}

The analysis of regression balances using t-statistics showed the significance of all factors taken into account in this model. Evaluation of the main parameters of the received equations of multiple linear regression leads to the conclusion that the presented model has high significance (level of significance of the Fisher criterion $\mathrm{F}<0.05$ for each of the cases); multiple correlation coefficient for the equations is not less than 0.87 , which characterizes a strong relationship of the grains mass with the initial agroecological factors.

From these parameters, we can conclude that the model is selected fairly accurately, but there are a number of factors that are not considered in the model, which can have a significant impact on the mass of wheat grains.

It should be marked that the coefficient for the first multiplier (the presence of fertilizers) is always positive, 
which indicates a positive effect of fertilizer application on the grain mass.

Studies performed on a large amount of data on changes in temperature and humidity in the Orenburg region allowed us to obtain forecast values of average annual temperature and humidity based on time series analysis [17]. The results obtained in this study can be used to obtain forecast yield values for the next three years (table 2).

Table 2 Forecast values of wheat grains mass, taking into account the dates and norms of sowing

\begin{tabular}{|c|c|c|c|c|}
\hline \multirow{3}{*}{ Years } & \multirow{3}{*}{ Sowing dates } & \multicolumn{3}{|c|}{ Seeding rate, $\mathbf{k g} / \mathbf{h a}$} \\
\cline { 2 - 5 } & & $\mathbf{2 , 5}$ & $\mathbf{3 , 5}$ & $\mathbf{4 , 5}$ \\
\hline \multirow{3}{*}{2020} & 1 period & 51,2 & 52,1 & 49,3 \\
\cline { 2 - 5 } & 2 period & 43,8 & 48,9 & 47,2 \\
\cline { 2 - 5 } & 3 period & 46,7 & 45,5 & 48,1 \\
\hline \multirow{3}{*}{2021} & 1 period & 50,9 & 44,4 & 46,2 \\
\cline { 2 - 5 } & 2 period & 50,6 & 41,7 & 42,2 \\
\hline \multirow{3}{*}{2022} & 3 period & 44,9 & 51,3 & 43,1 \\
\cline { 2 - 5 } & 1 period & 54,1 & 49,7 & 52,3 \\
\cline { 2 - 5 } & 2 period & 45,6 & 42,8 & 47,6 \\
\hline
\end{tabular}

The values obtained in table 2 allow producers to obtain the maximum grain mass by selecting the sowing dates and seeding rates. Analysis of the obtained values showed that, the most rational choice of technology of cultivation in 2020 is the first period of sowing with a seeding rate of $3.5 \mathrm{~kg} / \mathrm{ha}$, which will allow you to obtain the mass of 1000 grains in the amount of 52.1 In 2021 due to climate fluctuations, the most productive is sowing the same seed rate, but on the third sowing date that will allow you to $51.3 \mathrm{~g}$. mass of 1000 grains. Finally, in 2021, it is necessary to reduce the seeding rate to $2.5 \mathrm{~kg} / \mathrm{ha}$, while sowing must be carried out in the first term, which will ensure the maximum grain mass index of $54.1 \mathrm{~g}$.

Thus, the developed models give an accurate idea of what sowing date and what seeding rate should be observed to obtain optimal results.

The obtained models are quite difficult to read manually, so you need to create an algorithm for the subsequent development of a decision support system. The algorithm is based on the previously described development of a business process transformation model in agriculture, according to which cultivation should be accompanied by automated weather data management systems [18].

The algorithm is shown in Figure 1.

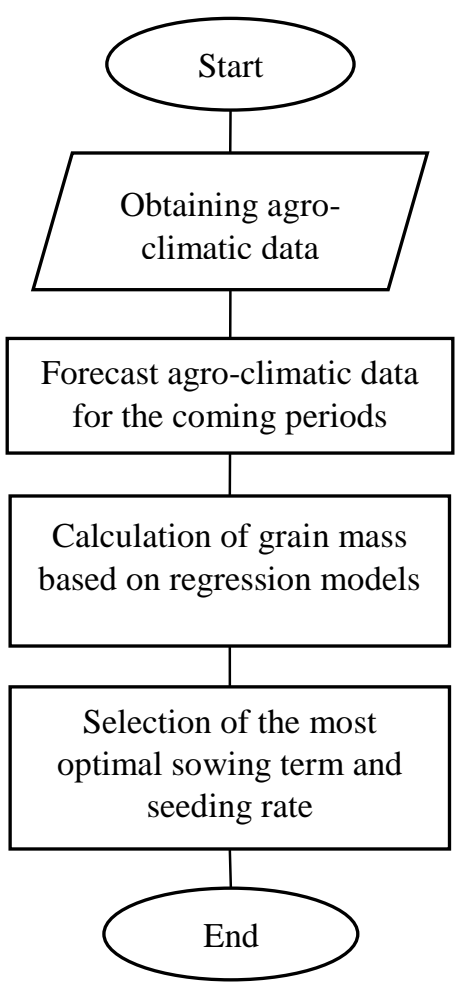

Figure 1 Decision-making algorithm for obtaining the maximum grain mass value based on agro-climatic data 
[3] Shcherbina T.A. Digital transformation of agriculture of the Russian Federation: experience and prospects // Russia: trends and development prospects. 2019.No. 141. P. 450-453.

\section{CONCLUSION}

The paper considers the influence of climate factors on the final productivity of agricultural enterprises. It is determined that the current climate changes can have a significant impact on the final productivity of an agricultural enterprise and, as a result, requires correction by methods of agricultural technologies. At the same time, it is necessary to obtain accurate and reliable data on changes in climate conditions and their impact on productivity, which will allow enterprises to use their land, labor, financial and other resources most effectively.

The influence of agro-climatic factors on wheat grain mas was evaluated by regression analysis using the least squares method. As a result, for each sowing date and seeding rate, specific equations of the influence of agro-climatic factors on the grain mass are obtained. The use of forecast values of temperature and humidity allowed us to obtain forecast values for the grain mass, calculated using previously compiled dependence equations. The obtained values allow us to make an optimal choice of sowing dates and seeding rates, taking into account the forecast of temperature and humidity.

Based on the obtained regression equations, a decisionmaking algorithm is constructed, which, in the future, can be used in a specialized decision support system. The obtained algorithm allows you to quickly and effectively predict the grain mass or the upcoming period and select the optimal sowing dates and seeding rates.

\section{ACKNOWLEDGMENT}

The studies were supported by a grant from the President of the Russian Federation for state support of leading scientific schools of the Russian Federation (SS-2502.2020.9), as well as in accordance with the research plan for 20192020 of the Federal Research Centre of Biological Systems and Agro-technologies of the Russian Academy of Sciences (No. 0761-2019 0004).

\section{REFERENCES}

[1] Ananyev M.A. Application of information technology in the agricultural sector / M.A. Ananyev, Yu.V. Ukhtinskaya. - URL: www.sisupr.mrsu.ru.

[2] Departmental project "Digital Agriculture": the official publication. - M.: FSINI "Rosinformagroteh", 2019. - $48 \mathrm{p}$.
[4] Veklenko V.I., Alkhastova E.M. The effectiveness of state regulation of agriculture // Bulletin of the Kursk State Agricultural Academy. 2017. No2. P. 51-56.

[5] Sandakova G.N., Besaliev I.N., Panfilov A.L., Akimov S.S. Cumulative indicator of quality of grain for strong wheat for conditions of strongly continental climate Collected at: IOP Conference Series: Earth and Environmental Science The proceedings of the conference AgroCON-2019. 2019. P. 012098.

[6] Toscano P., Genesio L., Crisci A., Vaccari F.P., Gioli B., Ferrari E., Cava P.L., Porter J.R. Empirical modeling of regional and national durum wheat quality // Agricultural and Forest Meteorology. - 2015. - T. 204. P. 67-78.

[7] Brankovic G. R., Dodig D., Zoric, M. Z., SurlanMomirovic G. G., Dragicevic V., Duric N. Effects of climatic factors on grain vitreousness stablitv and heritabilitv in durum wheat // Turkish journal of agriculture and forestry. - 2014. - T. 38. - No. 4. - C. 429440.

[8] Asseng S, Bar-Tal A., Bowden J. W., Keating B. A., Van Herwaarden A., Palta J. A., Huth N. I., Probert M. E. Simulation of grain protein content with APSIMNwheat// European journal of agronomy. - 2002. - T. 16. - No. 1. - P. 25-42.

[9] Hollins P.D., Kettlewell P.S., Peltonen-Sainio P., Atkinson M.D. Relationships between climate and winter cereal grain quality in Finland and their potential for forecasting // Agricultural and food science. - 2004. T. 13. - No. 3. - P. 295-308.

[10] Haboudane D., Miller J.R., Tremblay N., ZarcoTejada P.J., Dextraze L. Integrated narrow-band vegetation indices for prediction of crop chlorophyll content for aplication to precision agriculture // Remote Sensing of Environment. - 2002. - T. 81. - No. 2-3. - P. $416-426$

[11] Brushkov A.I. Innovative technologies of cultivation of grain crops using computers // Modern high technology. - 2005. - No. 9. - P. 12-14.

[12] Degtyareva G.V. Weather, crop and grain quality of spring wheat. M .: Gidrometeoizdat, 1981. P.196. 
[1]3 Pakhotina I.V., Kolmakov Yu.V., Evdokimov M.G. The effectiveness of the system for assessing the quality of durum wheat // Vestnik AGAU. - 2015. - No. 8 (130). - P. 14-18.

[14] Stroganova M.A. Mathematical modeling of crop quality formation. Leningrad. Gidrometeoizdat, 1986. $148 \mathrm{p}$.

[15] Pavlova V.N. The problem of assessing the impact of climate change on the productivity of the agricultural sector of Russia: methodology, models, calculation results // Bulletin of the Samara Scientific Center of the Russian Academy of Sciences. 2009. No. 1-7. P.15951600 .

[16] Tobratov S.A., Zheleznova O.S. Productivity of agricultural ecosystems and landscape and climatic factors // Bulletin of the Ryazan State University. S.A. Yesenin. 2011. No33.

[17] Sandakova G.N., Besaliev I.N., Panfilov A.L., Karavaitsev A.L., Kiyaeva E.V., Akimov S.S. Influence of agrometeorological factors on wheat yields Collected: IOP Conference Series: Earth and Environmental Science The proceedings of the conference AgroCON2019. 2019. P. 012022.

[18] Akimov, SS Business process modeling within the digital economy development framework [Electronic resource] / SS Akimov // Modern Management Trends and the Digital Economy: from Regional Development to Global Economic Growth (MTDE 2019): Proceedings of the 1st International Scientific, 14 -15 Apr. 2019, Yekaterinburg, Russia. - Electronic data. - Paris: Atlantis Press, 2019. - Vol. 81. - P. 262-267 